\section{ORIG INAL ARTICLE}

\title{
No differences between men and women in adverse drug reactions related to psychotropic drugs: a survey from France, Italy and Spain
}

\author{
Paola D’Incau ${ }^{\mathrm{a}}$, Maryse Lapeyre-Mestre ${ }^{\mathrm{b}, \mathrm{c}}$, Alfonso Carvajal ${ }^{\mathrm{d} *}$, \\ Monia Donati ${ }^{\mathrm{a}}$, Inés Salado ${ }^{\mathrm{d}}$, Lauriane Rodriguez ${ }^{\mathrm{b}}$, María Sáinz $^{\mathrm{d}}$, \\ Antonio Escudero ${ }^{\mathrm{d}}$, Anita Conforti ${ }^{\mathrm{a}}$ \\ ${ }^{\mathrm{a} D}$ Dipartimento di Sanità Pubblica e Medicina di Comunità, Sezione di Farmacologia, Università di Verona, Verona, \\ Italy \\ ${ }^{\mathrm{b}}$ Equipe de Pharmacoépidémiologie, INSERM 1027, Université Paul Sabatier, Toulouse, France \\ ${ }^{\mathrm{c}}$ Centre Midi-Pyrénées de Pharmacovigilance et d'Information sur le Médicament, Service de Pharmacologie Clinique, \\ Centre Hospitalier Universitaire, Toulouse, France \\ ${ }^{\mathrm{d}}$ Centro de Estudios sobre la Seguridad de los Medicamentos, Universidad de Valladolid, Valladolid, Spain
} revised 3 February 2013; accepted 15 March 2013

*Correspondence and reprints: carvajal@ife.uva.es accepted 15 March 2013 carvajare uva.es
Received 30 July 2012;

\section{Keywords}

gender,

pharmacovigilance,

psychotropics,

reporting

\begin{abstract}
A B STRACT
A large number of studies have suggested that being a woman represents a potential risk factor for the development of adverse drug reactions (ADRs). The aim of this study is to further explore the differences between men and women with regard to reported ADRs, particularly those associated with psychotropic drugs. We used spontaneous reports of suspected ADRs collected by Midi-Pyrénées (France), Veneto (Italy) and Castilla y León (Spain) Regional Pharmacovigilance Centres (January 2007-December 2009). All the reports including a psychotropic medication were selected in a first step; age distribution, seriousness and type of ADRs were compared between men and women. Reports of nonpsychotropic drugs were similarly identified and treated. The absolute number of reports and the proportion, considering population, were higher in women than in men. This was observed for all reports, but was particularly higher for psychotropic drugs (592 vs. $375 ; P<0.001)$ than for nonpsychotropics drugs (5193 vs. $4035 ; P<0.001$ ). Antidepressants were the most reported (women, 303; men, 141; $P<0.001$ ); the reporting rates (number of reports divided by exposed patients in the same period, estimated through sales data) for these drugs, however, were not significantly different between women ( 0.87 cases per 10000 treated persons per year) and men (0.81 cases per 10000 treated persons per year). Although there was a higher number of reports of ADRs in women, ADR reporting rates might be similar as highlighted by the case of antidepressants. Antidepressant ADRs in fact were similarly reported in men and in women. Gender differences are sometimes subtle and difficult to explore. International networks, as the one established for this study, do contribute to better analyse problems associated with medications.
\end{abstract}




\section{INTRODUCTION}

Adverse drug reactions (ADRs) represent an important public health problem; it is estimated that ADRs are identified in approximately $10 \%$ of patients taking a drug [1] and account for 3-6\% of admissions to hospital [2-5]. It has been suggested that being a woman represents a potential risk factor for the development of ADRs [6-13]; in some studies, women appeared with a 1.5- to 1.7-fold higher risk of developing an ADR as compared to men $[7,11,13,14]$. Although sex- and gender-specific differences in drug susceptibility are often assumed $[10,11,15]$, the evidence so far is limited. Actually, sex- and gender-specific differences in ADRs have not been systematically described; to date, only few studies have addressed this topic and there is only one with information coming from spontaneous reporting programmes [9].

In particular, psychotropic drugs have been shown to be one of the most frequently reported drug classes to elicit an adverse reaction, both in men and in women $[14,16]$. On the basis of these assumptions, the aim of this study was to further learn the differences between men and women with regard to reported ADRs, particularly those associated with psychotropic drugs.

\section{METHODS}

For the purpose, ADRs information coming from spontaneous reporting to the Midi-Pyrénées (France), Veneto (Italy) and Castilla y León (Spain) Regional Pharmacovigilance Centres was used; this information had been gathered between 1 January 2007 and 31 December 2009. All the reports comprising a psychotropic medication - antipsychotics, hypnotics, anxiolytics, antidepressants or stimulants - according to the 4th level of the Anatomical Therapeutic Chemical classification (ATC) [17] were selected in a first step; age distribution, seriousness and, for some class, type of ADRs, were compared between men and women. Age was subdivided into four categories: $\leq 18$ years, 19 59 years, 60-79 years and $\geq 80$ years; reports were excluded if age or sex was not stated or if age was under 1 year (ADRs reported after in uterus exposure during pregnancy were not considered). Seriousness was defined according to the World Health Organization (WHO) definition [18]; the adverse reactions reported were coded using Preferred Terms (PTs) and classified by System Organ Class (SOC), according to
WHO-ART hierarchy (World Health Organization Adverse Reaction Terms) [19]. All ADRs were taken into account if the causality was at least possible with the algorithms used in each country. Reports of nonpsychotropic drugs were similarly identified and analysed.

For all reports, we compared ratios calculated as follows: number of women reports/number of women inhabitants divided by number of men reports/number of men inhabitants. The null hypothesis was that men and women reports were equally distributed whatever the class of drug involved in the ADRs. Distribution of reports by age and seriousness in men and women was also studied. Reporting rates in those actually exposed patients and their 95\% confidence intervals (CIs) were calculated. These rates were estimated by dividing the number of reports by the number of exposed patientyears; the number of patient-years, in turn, was calculated from sales data expressed as defined daily dose (DDD) per 1000 inhabitants per year - 365 DDDs account for a patient treated per 1 year. These reporting rates were estimated on the assumption that the exposed population was large and the number of ADRs reports was small. Midi-Pyrénées consumption data were obtained from the medical regional department of the French Health Insurance System (Caisse Nationale d'Assurance Maladie des Travailleurs Salariés: CNAM-TS); Italian consumption data were obtained from Cineca (Centro di Supercalcolo, Consorzio di Università); and Spanish data consumption was obtained from the CONCYLIA database (Sistema de Información de Farmacia. Gerencia Regional de Salud de Castilla y León).

Descriptive statistics were used to summarize the general characteristics of the reports for psychotropic drugs of interest and the reference group. To compare categorical variables between women and men, the Pearson's chi-squared test was used; a $P$-value of $<0.05$ was considered statistically significant. The statistical analyses were performed with Epi-Info software (3.5.1 version).

\section{RESULTS}

After excluding those reports in which the age and/or sex were not available and those under 1 year, a total of 10195 reports fulfilled established criteria and were selected for the study (France, $n=5479$; Italy, $n=3644$; Spain, $n=1072$ ): 967 included at least one psychotropic medication and 9228 all other nonpsychotropic medications. Of those 967 psychotropic 
reports, 592 (61\%) referred to women, while 375 (39\%) did to men; the corresponding figures for nonpsychotropic reports were 5193 (56\%) and 4035 (44\%). The distribution of reports according to sex and their ratios are shown in Table I. Number of reports per 100000 inhabitants and year were 64, 25 and 14 for France, Italy and Spain, respectively.

Age distributions of reports were significantly different between men and women for all medications and seriousness (Table II); the only exception was that in nonserious psychotropic reports.

\section{Antidepressant-focused analysis}

The 444 antidepressant reports (women, 303; men, 141) account for 667 ADRs (women, 434; men, 233), the number of reactions per report being higher in men than in women (1.65 vs. 1.43). The most reported ADRs, both for women and men, were those classified as 'Central and peripheral nervous system disorders' (e.g. dizziness, dyskinesia and vertigo) (women, 107; men, 46) (Figure 1). The only reactions found to be reported significantly less often in women were those grouped into 'Psychiatric disorders' (e.g. anxiety, somnolence and insomnia) $(P<0.001)$.

Because the number of reports was by far higher for antidepressants (Table I), a more detailed analysis was performed for the main drugs of this class (Table III). Differences between number of reports for these drugs in women (196) and in men (46) were statistically significant $(P<0.001)$; women also consumed more antidepressants than men (23.0 DDD per 1000 inhabitants per day vs. 12.6 DDD per 1000 inhabitants per day). Reporting incidence per treated patients, however, was not significantly different between men $(0.81$ cases per 10000 treated persons per year) and women (0.87 cases per 10000 treated persons per year).

\section{DISCUSSION}

To our knowledge, this is the first multinational study focused on differences between men and women carried out with spontaneously reported ADRs to pharmacovigilance systems. The opportunity to combine data from three different areas in southern Europe has yielded a large number of reports to analyse; in particular, those related to psychotropic medications represent almost 1000 for the 3 years considered. Although the number of reports in these countries was different, it does not preclude an overall analysis; in this analysis, the absolute number of reports and the proportion, referred to the population, were by far higher in women than in men. This was observed for all type of reports, but was particularly higher for those reports including psychotropic than for those with nonpsychotropics drugs; this is coincidental with what has been observed in other studies [10,12,16,20-24]. At first glance, these findings do suggest women's propensity to experiencing adverse drug reactions. However, in

\begin{tabular}{|c|c|c|c|c|c|}
\hline & \multicolumn{2}{|l|}{ Women } & \multicolumn{2}{|l|}{ Men } & \multirow[b]{2}{*}{ Ratio } \\
\hline & Reports & $\begin{array}{l}\text { Reports per } 10000 \\
\text { inhabitants }^{\mathrm{a}}\end{array}$ & Reports & $\begin{array}{l}\text { Reports per } 10000 \\
\text { inhabitants }^{\mathrm{a}}\end{array}$ & \\
\hline Nonpsychotropic drugs & 5193 & 9.96 & 4035 & 8.04 & 1.24 \\
\hline Psychotropic drugs ${ }^{b}$ & 592 & 1.14 & 375 & 0.75 & $1.52^{c}$ \\
\hline Antipsychotics & 229 & 0.44 & 176 & 0.35 & 1.26 \\
\hline Anxiolytics & 132 & 0.25 & 93 & 0.18 & 1.39 \\
\hline Hypnotics/sedatives & 89 & 0.17 & 59 & 0.12 & 1.42 \\
\hline Antidepressants & 303 & 0.58 & 141 & 0.28 & 2.07 \\
\hline Psychostimulants $^{d}$ & 13 & 0.02 & 8 & 0.02 & 1.00 \\
\hline
\end{tabular}

Table I Reports related to psychotropic and all other nonpsychotropic drugs. Comparison between men and women.

${ }^{a}$ Total population for the three regions, 10227170 inhabitants (women, 5210 583; men, 5016 587).

bBecause some patients took more than one psychotropic simultaneously, the sum of the number of reports in each class $(n=1243)$ is higher than the total number of psychotropic reports $(n=967)$.

${ }^{c}$ The corresponding data for the three regions were, respectively, 1.49 Midi-Pyrénées (women reports $=440$, women population $=1457$ 696; men reports $=279$, men population $=1379804$ ), 1.23 Veneto (women reports $=73$, women population $=2464895$; men reports $=57$, men population $=2367445$ ) and 2.00 Castilla y León (women reports $=79$, women population $=1287$ 992; men reports $=39$, men population $=1269$ 338). Source: French census, http://www.insee.fr; Italian census, http://demo.istat.it; Spanish census, http://www.ine.es.

${ }^{\mathrm{d} T h e y ~ i n c l u d e ~ p s y c h o s t i m u l a n t s, ~ a g e n t s ~ u s e d ~ f o r ~ a t t e n t i o n-d e f i c i t ~ h y p e r a c t i v i t y ~ d i s o r d e r ~ a n d ~ n o o t r o p i c s . ~}$ 
Table II Distribution of reports by age and seriousness. Comparison between men and women ${ }^{\mathrm{a}}$.

\begin{tabular}{|c|c|c|c|c|}
\hline & \multicolumn{2}{|c|}{ Psychotropic reports } & \multicolumn{2}{|c|}{ Nonpsychotropic reports } \\
\hline & Women (\%) & Men (\%) & Women (\%) & Men (\%) \\
\hline \multicolumn{5}{|l|}{ Age } \\
\hline$\leq 18$ & $5(2)$ & $10(6)$ & $690(13)$ & 755 (19) \\
\hline $19-59$ & $134(59)$ & $117(66)$ & $2132(41)$ & $1511(37)$ \\
\hline $60-79$ & $48(21)$ & $29(16)$ & $1503(29)$ & $1330(33)$ \\
\hline$\geq 80$ & $42(18)$ & $20(11)$ & $868(17)$ & 439 (11) \\
\hline \multicolumn{5}{|l|}{ Seriousness } \\
\hline Serious & $96(100)$ & $85(100)$ & $1945(100)$ & $1693(100)$ \\
\hline$\leq 18$ & $0(0)$ & $5(6)$ & $127(7)$ & $166(10)$ \\
\hline $19-59$ & $44(46)$ & $51(60)$ & $734(38)$ & $615(38)$ \\
\hline $60-79$ & $24(25)$ & $16(19)$ & $592(30)$ & $603(37)$ \\
\hline$\geq 80$ & $28(29)$ & $13(15)$ & $492(25)$ & $255(16)$ \\
\hline Not serious & $133(100)$ & $91(100)$ & $3248(100)$ & $2396(100)$ \\
\hline$\leq 18$ & $5(4)$ & $5(5)$ & $563(17)$ & $589(25)$ \\
\hline $19-59$ & $89(67)$ & $67(74)$ & $1398(43)$ & $896(37)$ \\
\hline $60-79$ & $23(17)$ & $14(15)$ & $911(28)$ & $727(30)$ \\
\hline$\geq 80$ & $16(12)$ & $5(5)$ & $376(12)$ & $184(8)$ \\
\hline
\end{tabular}

aPearson's chi-square test: age: psychotropic male vs. psychotropic female, $P$-value $=0.03$; age: nonpsychotropic male vs. nonpsychotropic female, $P$-value $<0.001$; age: psychotropic male vs. nonpsychotropic male, $P$ value $<0.001$; age: psychotropic female vs. nonpsychotropic female, $P$ value $<0.001$; seriousness: psychotropic male serious vs. psychotropic female serious, $P$-value $=0.007$; seriousness: nonpsychotropic male serious vs. nonpsychotropic female serious, $P$-value $<0.001$; seriousness: psychotropic male serious vs. nonpsychotropic male serious, $P$-value $=0.0002$; seriousness: psychotropic female serious vs. nonpsychotropic female serious, $P$-value $=0.02$; seriousness: psychotropic male not serious vs. psychotropic female not serious, $P$-value $=0.3484$; seriousness: nonpsychotropic male not serious vs. nonpsychotropic female not serious, $P$-value $<0.001$; seriousness: psychotropic male not serious vs. nonpsychotropic male not serious, $P$-value $<0.001$; seriousness: psychotropic female not serious vs. nonpsychotropic female not serious, $P$-value $<0.001$.

the present analysis, when considering antidepressant drug consumption, the resulting reporting rate was only marginally higher in women but it did not significantly differs between men and women (Table III); actually, the overall number of reactions per report for antidepressants was even higher in men than in women. This could only be analysed for antidepressants. These latter results are not coincidental with the general belief of a higher susceptibility to ADRs in women and pose the question of the real influences of sex and gender. Certainly, reporting is not the same than real occurrence.

The Merriam-Webster dictionary (http://www. merriam-webster.com/dictionary) defines sex as "either of the two major forms of individuals that occur in many species and that are distinguished respectively as female or male especially on the basis of their reproductive organs or structures'; gender meanwhile is defined as 'the behavioral, cultural, or psychological traits typically associated with sex'; similar definitions can be found in the Oxford English Dictionary (http:// www.oed.com/). Thus, sex-based differences in physical and physiological characteristics may contribute to interindividual pharmacokinetic and pharmacodynamic variability [15,20-31], while gender differences refer to a person's self-representation as male or female shaped by the individual economic, social, political and cultural status that might be of importance for the occurrence of ADRs [15,32]. Hence, the question as to whether ADRs occurrence does particularly depend on gender is controversially and ambiguously discussed in the literature [20-23]; in the literature, in fact, there are no clear limits between sex and gender perspectives; for instance, in a recent thorough review, differences in drug toxicity between men and women are presented as 'gender differences' [33].

Our current findings of a much higher number of reports in women (Table I) and the significantly different distribution by age and severity in men and women (Table II) are likely to reflect the pattern of use of certain medications, particularly psychotropics. This was already highlighted in the European Study of the Epidemiology of Mental Disorders (ESEMED), where a high prevalence of common mental disorders in women was identified $[25,26]$. Another plausible explanation, closely related to being a woman, might be the increased life expectancy that leads elderly women to become more fragile and subject to chronic debilitating conditions.

The finding of similar reporting rates for antidepressants was not expected. In principle, as we do not have further data upon what occurs with the other drugs, we cannot be sure whether reporting for all of them behave in the same manner as it does with antidepressants. In any case, and even assuming similar reporting rates, we cannot say the occurrence is the same; the occurrence in fact might be different and then being balanced for a differential reporting. At this regard, it is important to underline that while occurrence can be influenced by sex or gender, reporting - chiefly based on occurrence - can be markedly influenced by gender condition. Different possibilities to explain gender differences include the following: women suffering particular diseases; women attending medical practices more often; women complaining more than men; doctors underestimating adverse effects in women, particularly 


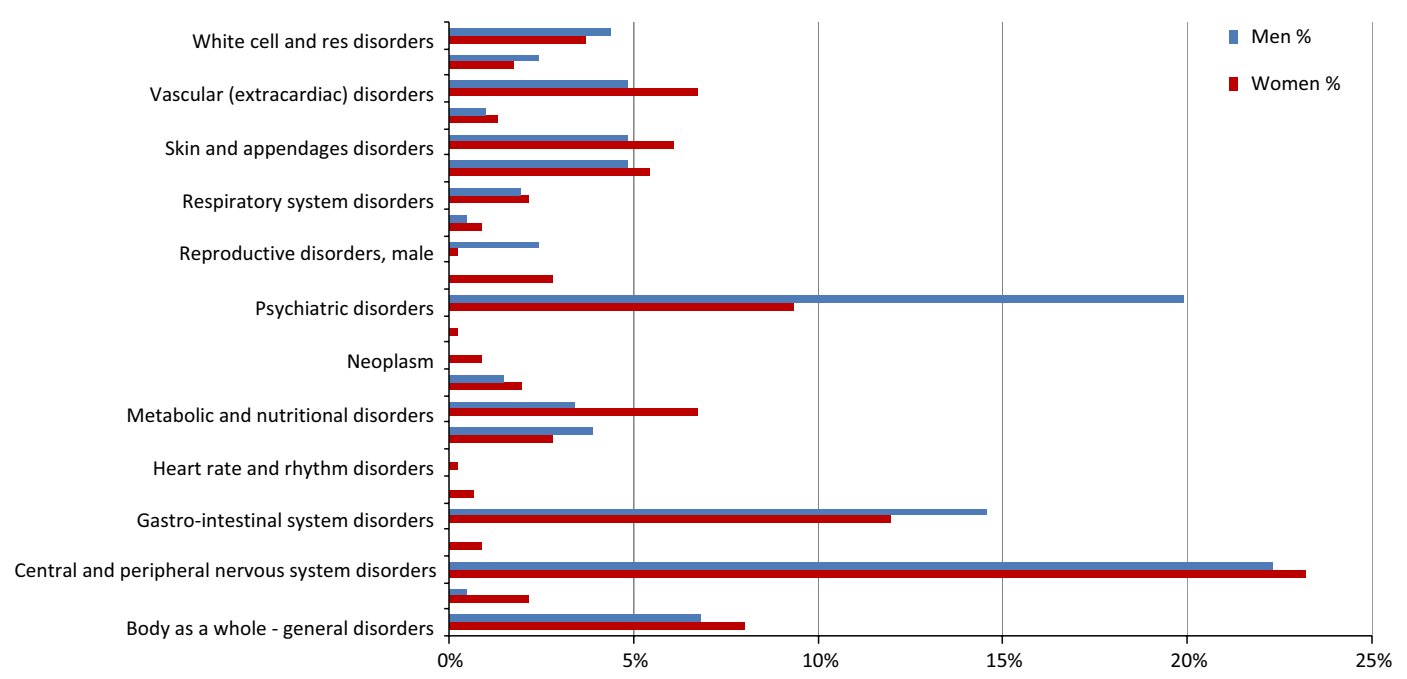

Figure 1 Distribution of the adverse drug reactions associated with antidepressants by organs and systems. Comparison between men (blue) and women (red).

\begin{tabular}{|c|c|c|c|c|c|c|}
\hline & \multicolumn{2}{|c|}{$\begin{array}{l}\text { Number of } \\
\text { reports }\end{array}$} & \multicolumn{2}{|c|}{$\begin{array}{l}\text { DDD per } 1000 \\
\text { inhabitants day }\end{array}$} & \multicolumn{2}{|c|}{$\begin{array}{l}\text { Reporting rate per } 10000 \text { treated } \\
\text { patient-years }(95 \% \mathrm{Cl})\end{array}$} \\
\hline & Women & Men & Women & Men & Women & Men \\
\hline Citalopram & 28 & 11 & 3.05 & 1.23 & $0.99(0.62-1.35)$ & $0.99(0.49-1.77)$ \\
\hline Duloxetine & 45 & 19 & 2.00 & 0.79 & $2.25(1.59-2.91)$ & $2.34(1.41-3.65)$ \\
\hline Escitalopram & 40 & 18 & 7.38 & 3.05 & $0.60(0.42-0.79)$ & $0.66(0.39-1.05)$ \\
\hline Paroxetine & 46 & 28 & 6.67 & 5.53 & $0.70(0.50-0.91)$ & $0.56(0.35-0.76)$ \\
\hline Venlafaxine & 37 & 17 & 4.86 & 1.99 & $0.83(0.57-1.10)$ & $0.94(0.55-1.51)$ \\
\hline Total & 196 & 93 & 23.96 & 12.59 & $0.87(0.75-0.99)$ & $0.81(0.65-0.97)$ \\
\hline
\end{tabular}

Table III Reporting rates of the main antidepressants. Comparison between men and women. those of psychotropic drugs, while they consider important to detect the ADRs when occurring in men [2830]. To further complicate things, as doctors are men or women, gender perspective would be present when identifying and reporting ADRs. Thus, it is clear that gender influence does exist, but it is difficult to assess it as much in occurrence of ADRs as in reporting.

For the class of antidepressants, citalopram, duloxetine, escitalopram, paroxetine and venlafaxine were the drugs most frequently involved in reports; of those, duloxetine appears with the highest ADR reporting rate (Table III). These five antidepressants are among the most prescribed SSRIs in Italy, France and Spain [34-38]. Apart from this, adverse drug reactions are important determinants of nonadherence to antidepressant treatment, but their assessment is complicated by overlap with depressive symptoms and lack of reliable self-report measures [39]. It has been previously reported that adverse reactions are more frequently experienced by individuals with more severe depression [40]; this is explained by an increased sensitivity and attention to physical discomfort that accompanies depressed mood.

Although pharmacovigilance, by means of spontaneous reporting programmes, is an essential activity for detecting ADRs and thus for establishing the safety of a drug, the analysis of spontaneous reports has important limitations. The information is neither always complete nor homogeneous; several reporting biases have been described; under-reporting is very common - it is estimated that only a small proportion of all ADRs are reported [41,42]. Nevertheless, because this is a unique and valuable material upon ADRs, it is worthy to explore it; it permits to find clues for new and better approaches to learning and thinking over sex and gender differences in drug responses. All in all, 
it should be stated that international networks, as the one established for the present study, do contribute to better analyse problems associated with medications.

\section{ACKNOWLEDGEMENTS}

We would like to thank Dr. Robert Bourrel, MD, and Carole Suarez, statistician, from the department of the French Health Insurance System (Caisse Nationale d'Assurance Maladie des Travailleurs Salariés: CNAM-TS, France) for their help in collecting French data consumption. Also, we would like to acknowledge Prof. JL Montastruc, Head of the MidiPyrénées Pharmacovigilance Centre (France) who gave us access to the data on Midi-Pyrénées ADRs. We would like to thank also Dr. Laure Pourcel (Centre Midi-Pyrénées de Pharmacovigilance et d'Information sur le Médicament, Service de Pharmacologie Clinique, Centre Hospitalier Universitaire, Toulouse, France) and Dr. Laura Bisoffi (Head of Biostatistics and Research Support Unit University of Verona) for their help with the statistics. We thank also Prof. Roberto Leone, Dr. Ugo Moretti, Dr. Lara Magro and Dr. Riccardo Lora (Department of Medicine and Public Health Section of Pharmacology University of Verona) for their support. We particularly appreciate those health professionals who reported adverse events.

\section{FUNDING}

This project was self-financed by the regional pharmacovigilance centres of Midi-Pyrénées, Veneto and Castilla y Leon; the latter receives funds from the Regional Authority's General Directorate of Public Health Junta de Castilla y León.

\section{REFERENCES}

1 Thomsen L.A., Winterstein A.G., Søndergaard B., Haugbølle L.S., Melander A. Systematic review of the incidence and characteristics of preventable adverse drug events in ambulatory care. Ann. Pharmacother. (2007) 41 1411-1426.

2 Leendertse A.J., Egberts A.C., Stoker L.J., van den Bemt P.M. HARM Study Group Frequency of and risk factors for preventable medication-related hospital admissions in the Netherlands. Arch. Intern. Med. (2008) 168 1890-1896.

3 Davies E.C., Green C.F., Taylor S., Williamson P.R., Mottram D.R., Pirmohamed M. Adverse drug reactions in hospital in-patients: a prospective analysis of 3695 patient-episodes. PLoS ONE (2009) 4 e4439.
4 Kongkaew C., Noyce P.R., Ashcroft D.M. Hospital admissions associated with adverse drug reactions: a systematic review of prospective observational studies. Ann. Pharmacother. (2008) 42 1017-1025.

5 Pouyanne P., Haramburu F., Imbs J.L., Bégaud B. Admissions to hospital caused by adverse drug reactions: cross sectional incidence study. French pharmacovigilance centres. BMJ (2000) 3201036.

6 Tran C., Knowles S.R., Liu B.A., Shear N.H. Gender differences in adverse drug reactions. J. Clin. Pharmacol. (1998) 38 1003-1009.

7 Martin R.M., Biswas P.N., Freemantle S.N., Pearce G.L., Mann R.D. Age and sex distribution of suspected adverse drug reactions to newly marketed drugs in general practice in England: analysis of 48 cohort studies. Br. J. Clin. Pharmacol. (1998) 46 505-511.

8 Fattinger K., Roos M., Vergères P. et al. Epidemiology of drug exposure and adverse drug reactions in two Swiss departments of internal medicine. Br. J. Clin. Pharmacol. (2000) 49 158-167.

9 Montastruc J.L., Lapeyre-Mestre M., Bagheri H., Fooladi A. Gender differences in adverse drug reactions: analysis of spontaneous reports to a Regional Pharmacovigilance Centre in France. Fundam. Clin. Pharmacol. (2002) 16 343-346.

10 Franconi F., Brunelleschi S., Steardo L., Cuomo V. Gender differences in drug responses. Pharmacol. Res. (2007) 55 $81-95$.

11 Zopf Y., Rabe C., Neubert A. et al. Women encounter ADRs more often than do men. Eur. J. Clin. Pharmacol. (2008) 64 999-1004.

12 Zopf Y., Rabe C., Neubert A. et al. Gender-based differences in drug prescription: relation to adverse drug reactions. Pharmacology (2009) 84 333-339.

13 Rodenburg E.M., Stricker B.H., Visser L.E. Sex-related differences in hospital admissions attributed to adverse drug reactions in the Netherlands. Br. J. Clin. Pharmacol. (2011) 71 95-104.

14 Rademaker M. Do women have more adverse drug reactions? Am. J. Clin. Dermatol. (2001) 2 349-351.

15 Gandhi M., Aweeka F., Greenblatt R.M., Blaschke T.F. Sex differences in pharmacokinetics and pharmacodynamics. Annu. Rev. Pharmacol. Toxicol. (2004) 44 499-523.

16 Haack S., Seeringer A., Thürmann P.A., Becker T., Kirchheiner J. Sex-specific differences in side effects of psychotropic drugs: genes or gender? Pharmacogenomics (2009) $101511-2156$.

17 WHO Collaborating Centre for Drug Statistics Methodology (2010) Guidelines for ATC classification and DDD assignment. Available at: http://www.whocc.no/filearchive/publications/ 2010guidelines.pdf (accessed 24 March 2011)

18 The Uppsala Monitoring Centre (2008) Causality Assessment of Suspected Adverse Reactions. Available at: http://www. who-umc.org/DynPage.aspx?id=22682 (accessed 17 November 2010).

19 The Uppsala Monitoring Centre (2010) WHO Drug Dictionary. Availablet at: http://www.who-umc.org/DynPage. aspx?id=13120\&mn=m (accessed 17 November 2010). 
20 Camargo A.L., Cardoso Ferreira M.B., Heineck I. Adverse drug reactions: a cohort study in internal medicine units at a university hospital. Eur. J. Clin. Pharmacol. (2006) 62 143149.

21 Carbonin P., Pahor M., Bernabei R., Sgadari A. Is age an independent risk factor of adverse drug reactions in hospitalized medical patients? J. Am. Geriatr. Soc. (1991) 39 1093-1099.

22 Hoigne R., Sollberger J., Zoppi M. et al. Significance of age, sex, kidney function, atopy and number of prescriptions for the occurrence of adverse drug reactions, studied by multivariate statistical methods. Results from the Comprehensive Hospital Drug Monitoring Berne (CHDMB). Schweiz. Med. Wochenschr. (1984) 114 1854-1857.

23 van den Bemt P.M., Egberts A.C., Lenderink A.W. et al. Risk factors for the development of adverse drug events in hospitalized patients. Pharm. World Sci. (2000) 22 62-66.

24 Gray S.L., Mahoney J.E., Blough D.K. Adverse drug events in elderly patients receiving home health services following hospital discharge. Ann. Pharmacother. (1999) 331147 1153.

25 Alonso J., Angermeyer M.C., Bernert S. et al. Use of mental health services in Europe: results from the European Study of the Epidemiology of Mental Disorders (ESEMeD) project. Acta Psychiatr. Scand. Suppl. (2004) 420 55-64.

26 Verdoux H., Tournier M., Bégaud B. Pharmacoepidemiology of psychotropic drugs: examples of current research challenges on major public health issues. Epidemiol. Psichiatr. Soc. (2009) 18 107-113.

27 Cooperstock R. Psychotropic drug use among women. Can. Med. Assoc. J. (1976) 115 760-763.

28 Hohmann A.A. Gender bias in psychotropic drug prescribing in primary care. Med. Care (1989) 27 478-490.

29 Dennerstein L. Mental health, work, and gender. Int. J. Health Serv. (1995) 25 503-509.

30 Liebert M.A. Exploring the biological contributions to human health: does sex matter? J. Womens Health Gend. Based Med. (2001) $10433-439$.

31 Soldin O.P., Mattison D.R. Sex differences in pharmacokinetics and pharmacodynamics. Clin. Pharmacokinet. (2009) 48 143-157.
32 Verdonk P., Benschop Y.W., de Haes H.C., Lagro-Janssen T.L. From gender bias to gender awareness in medical education. Adv. Health Sci. Educ. Theory Pract. (2009) 14 135-152.

33 Nicolson T.J., Mellor H.R., Roberts R.R. Gender differences in drug toxicity. Trends Pharmacol. Sci. (2020) 31 108114.

34 Horwitz V.A., Wakefield C.J. The medicalization of sadness: how psychiatry transformed a natural emotion into a mental disorder. Salute e Società (2009) 249-66.

35 Pietraru C., Barbui C., Poggio L., Tognoni G. Antidepressant drug prescribing in Italy, 2000: analysis of a general practice database. Eur. J. Clin. Pharmacol. (2001) 57 605-609.

36 Olié J.P., Elomari F., Spadone C., Lépine J.P. Antidepressants consumption in the global population in France. Encephale (2002) 28 411-417.

37 Ubeda A., Cardo E., Sellés N., Broseta R., Trillo J.L., Fernández-Llimós F. Antidepressant utilization in primary care in a Spanish region: impact of generic and referencebased pricing policy (2000-2004). Soc. Psychiatry Psychiatr. Epidemiol. (2007) 42 181-188.

38 Arias L.H., Lobato C.T., Ortega S., Velasco A., Carvajal A., del Pozo J.G. Trends in the consumption of antidepressants in Castilla y León (Spain). Association between suicide rates and antidepressant drug consumption. Pharmacoepidemiol. Drug Saf. (2010) 19 895-900.

39 Caputi A.P., De Ponti F., Pagliaro L. Reazioni avverse a farmaci. Sospetto e diagnosi, Raffaello Cortina Editore, Milano, 2009.

40 Kornstein S.G., Schatzberg A.F., Thase M.E. et al. Gender differences in treatment response to sertraline versus imipramine in chronic depression. Am. J. Psychiatry (2000) 157 1445-1452.

41 Alvarez-Requejo A., Carvajal A., Bégaud B., Moride Y., Vega T., Arias L.H. Under-reporting of adverse drug reactions. Estimate based on a spontaneous reporting scheme and a sentinel system. Eur. J. Clin. Pharmacol. (1998) 54 483488.

42 Hazell L. Shakir SAW Under-reporting of adverse drug reactions: a systematic review. Drug Saf. (2006) $29385-$ 396. 